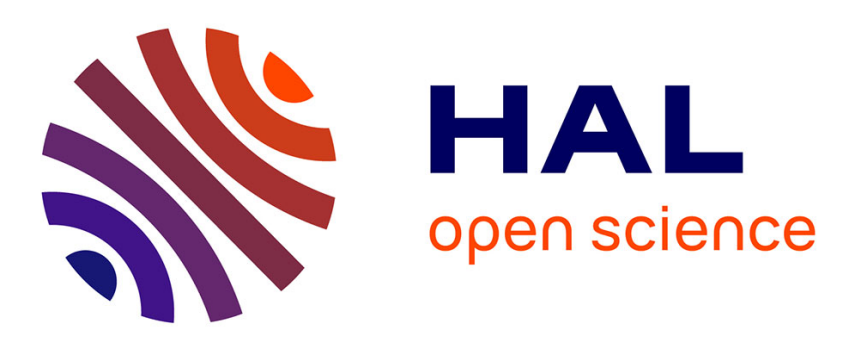

\title{
The efficacy of post porosity plasma protection against vacuum-ultraviolet damage in porous low-k materials
}

\author{
K. Lionti, Maxime Darnon, W. Volksen, T. Magbitang, G. Dubois
}

\section{To cite this version:}

K. Lionti, Maxime Darnon, W. Volksen, T. Magbitang, G. Dubois. The efficacy of post porosity plasma protection against vacuum-ultraviolet damage in porous low-k materials. Journal of Applied Physics, 2015, 117 (11), 10.1063/1.4915508 . hal-01916782

\section{HAL Id: hal-01916782 \\ https://hal.science/hal-01916782}

Submitted on 8 Nov 2018

HAL is a multi-disciplinary open access archive for the deposit and dissemination of scientific research documents, whether they are published or not. The documents may come from teaching and research institutions in France or abroad, or from public or private research centers.
L'archive ouverte pluridisciplinaire HAL, est destinée au dépôt et à la diffusion de documents scientifiques de niveau recherche, publiés ou non, émanant des établissements d'enseignement et de recherche français ou étrangers, des laboratoires publics ou privés. 


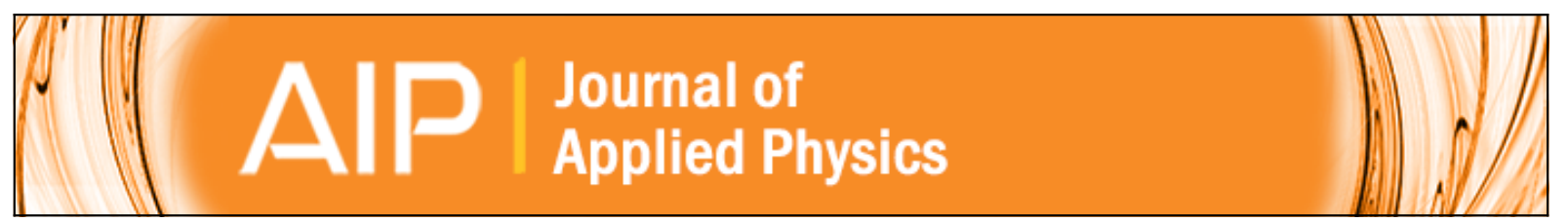

The efficacy of post porosity plasma protection against vacuum-ultraviolet damage in porous low-k materials

K. Lionti, M. Darnon, W. Volksen, T. Magbitang, and G. Dubois

Citation: Journal of Applied Physics 117, 113303 (2015); doi: 10.1063/1.4915508

View online: http://dx.doi.org/10.1063/1.4915508

View Table of Contents: http://scitation.aip.org/content/aip/journal/jap/117/11?ver=pdfcov

Published by the AIP Publishing

\section{Articles you may be interested in}

Effect of vacuum-ultraviolet irradiation on the dielectric constant of low-k organosilicate dielectrics

Appl. Phys. Lett. 105, 202902 (2014); 10.1063/1.4901742

Effects of plasma and vacuum-ultraviolet exposure on the mechanical properties of low-k porous organosilicate glass

J. Appl. Phys. 116, 044103 (2014); 10.1063/1.4891501

Bandgap measurements of low-k porous organosilicate dielectrics using vacuum ultraviolet irradiation Appl. Phys. Lett. 104, 062904 (2014); 10.1063/1.4865407

The effects of plasma exposure and vacuum ultraviolet irradiation on photopatternable low-k dielectric materials J. Appl. Phys. 114, 104107 (2013); 10.1063/1.4821065

Mechanism of plasma-induced damage to low-k SiOCH films during plasma ashing of organic resists J. Appl. Phys. 109, 033303 (2011); 10.1063/1.3544304

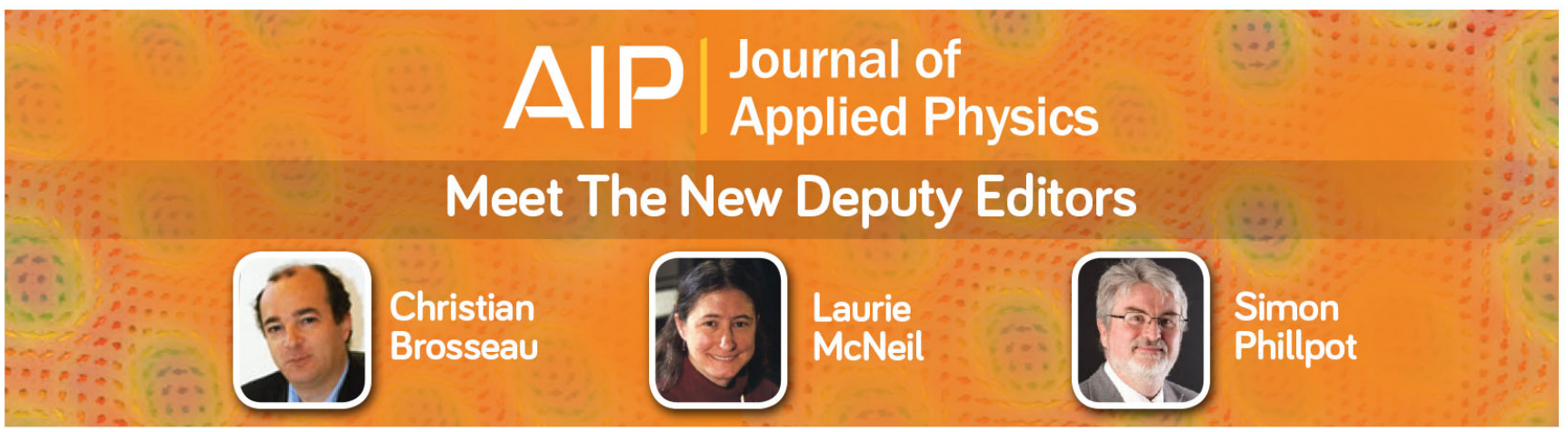




\title{
The efficacy of post porosity plasma protection against vacuum-ultraviolet damage in porous low-k materials
}

\author{
K. Lionti, ${ }^{1}$ M. Darnon, ${ }^{2}$ W. Volksen, ${ }^{1}$ T. Magbitang, ${ }^{2}$ and G. Dubois ${ }^{2, a)}$ \\ ${ }^{1}$ IBM Almaden Research Center, San Jose, California 95120, USA \\ ${ }^{2}$ CNRS/LTM, CEA/LETI-Minatec, 38054 Grenoble Cedex 09, France
}

(Received 9 December 2014; accepted 4 March 2015; published online 20 March 2015)

\begin{abstract}
As of today, plasma damage remains as one of the main challenges to the reliable integration of porous low-k materials into microelectronic devices at the most aggressive node. One promising strategy to limit damage of porous low-k materials during plasma processing is an approach we refer to as post porosity plasma protection $(\mathrm{P} 4)$. In this approach, the pores of the low-k material are filled with a sacrificial agent prior to any plasma treatment, greatly minimizing the total damage by limiting the physical interactions between plasma species and the low-k material. Interestingly, the contribution of the individual plasma species to the total plasma damage is not fully understood. In this study, we investigated the specific damaging effect of vacuum-ultraviolet (v-UV) photons on a highly porous, $\mathrm{k}=2.0$ low-k material and we assessed the $\mathrm{P} 4$ protective effect against them. It was found that the impact of the v-UV radiation varied depending upon the $\mathrm{v}-\mathrm{UV}$ emission lines of the plasma. More importantly, we successfully demonstrated that the $\mathrm{P} 4$ process provides excellent protection against v-UV damage. (C) 2015 AIP Publishing LLC. [http://dx.doi.org/10.1063/1.4915508]
\end{abstract}

\section{INTRODUCTION}

The general pathway to improve microprocessor performance has heavily relied upon the scaling to progressively smaller device dimensions. With regard to BEOL interconnects, it has led to an increase in RC delay (product of the line resistance $\mathrm{R}$ and capacitance $\mathrm{C}$ ). This challenge was addressed by switching from aluminum to copper technology (reducing $\mathrm{R}$ ) and integrating insulators with a lower dielectric constant (decreasing $\mathrm{C}$ ). The latter was achieved through the introduction of air in the form of pores into the low-k hybrid silica materials. ${ }^{1}$ Unfortunately, this leads to severe issues during integration as the increasing porosity negatively impacts the low-k material properties. First, they become more fragile due to the decrease in network connectivity and density, i.e., lower number of bridging bonds per volume unit. This issue was however addressed by increasing the hybrid silica network connectivity through the use of carbon bridged precursors, leading to improved low-k stiffness, fracture resistance, and interfacial adhesion. ${ }^{2-9}$ Second, highly porous low-k materials are a lot more prone to plasma damage due to a huge increase in accessible surface area. ${ }^{10-13}$ Over the past 15 years, a lot of efforts have been devised to either prevent or mitigate plasma damage. ${ }^{14}$ Among them, post-porosity plasma protection (P4) is the only strategy that takes advantage of the increasing porosity with decreasing dielectric constant in low-k materials. ${ }^{15-17}$

The P4 efficacy has already been demonstrated on a wide range of spin-on and PECVD dielectric materials on both blanket and patterned structures. ${ }^{17}$ It was shown that plasma damage is greatly mitigated when the porous low-k material is filled, due to the inaccessibility of harmful plasma species into

${ }^{\text {a)} E l e c t r o n i c ~ m a i l: ~ g d u b o i s @ u s . i b m . c o m . ~}$ the interior of the dielectric material. Consequently, the damage is localized at the low-k surface, while the bulk is kept intact.

In this study, we investigate the P4 efficacy against plasma damage generated by vacuum-ultraviolet (v-UV) photons with the aim to answer two key questions:

(a) Can the $\mathrm{P} 4$ process minimize the $\mathrm{v}-\mathrm{UV}$ photon damage? (b) Do v-UV photons negatively impact the organic filler?

Toward this end, we selected a highly porous $\mathrm{k}=2.0$ spin-on organosilicate and exposed it to two plasmas (with different v-UV spectra) typically employed in BEOL manufacturing: a fluorocarbon based plasma, used for etching purposes and an aggressive $\mathrm{O}_{2}$ plasma, employed in post-etch steps (photoresist removal, surface cleaning, defluorination, etc.). In order to eliminate all the plasma species except v-UV photons, a $\mathrm{MgF}_{2}$ window with a cut-off wavelength of $120 \mathrm{~nm}$ was used. The v-UV effect on the unfilled pristine low-k material varied with plasma chemistry: no structural change was evidenced in the case of the fluorocarbon based plasma, whereas a thin denser top layer was clearly detected on the dielectric material treated with the v-UV photons of the $\mathrm{O}_{2}$ plasma. When the same low-k material was filled with a PMMA-based filler, the v-UV radiation from the $\mathrm{O}_{2}$ plasma did not cause any change in low-k density or thickness, proving the efficacy of the P4 process against v-UV damage. Moreover, we also show that the filler appears to be unaffected by the v-UV photons (no cleavage or cross-linking) and that it can still be fully degraded after low-k processing.

\section{EXPERIMENT}

\section{A. Film preparation}

A $\mathrm{k}=2.0$ spin-on resin derived from an ethylene-bridged organosilicate precursor was selected for this study. ${ }^{4,5}$ To achieve such a low dielectric constant, the addition of a 
porogen in the sol-gel formulation was required. The porogen nature and quantity, along with the sol-gel conditions were optimized to generate $\mathrm{k}=2.0$ films. Films were deposited on $200 \mathrm{~mm} \mathrm{Si}$ wafers by spin-coating of the formulation followed by thermal cure at elevated temperatures. The thickness and the refractive index of each film were determined by spectral reflectivity. The film thickness was $207.5 \pm 2.5 \mathrm{~nm}$ with a corresponding refractive index at $633 \mathrm{~nm}$ of 1.27 for all the wafers, attesting of a good film homogeneity and reproducibility. A film porosity of $40 \%$ was measured by ellipsometric porosimetry using toluene as an adsorbent.

\section{B. Pore filling}

A detailed description of the filling process has been previously described. ${ }^{13,15}$ Typically, a filler solution comprised of a PMMA-type copolymer of proprietary composition and molecular weight in a compatible solvent was spincoated on top of the low-k film. The wafer was subsequently heated above the filler's $T_{g}$ to decrease the melt viscosity and allow for pore filling through capillary action. Finally, a solvent wash was performed on the low-k surface to remove the excess filler, also known as overburden. At this point, the refractive index and density of the filled films were measured by optical measurements and x-ray reflectivity, respectively; pore fill was found to be complete and homogeneous.

\section{Plasma treatments}

Two different plasma treatments were used to expose both filled and unfilled low-k materials. The plasma exposure experiments were performed in a $200 \mathrm{~mm}$ eMax chamber from Applied Materials described in previous studies. ${ }^{18}$ This chamber generates a magnetically enhanced capacitive coupled plasmas with $13.56 \mathrm{MHz}$ radiofrequency power and a rotating magnetic field at $0.2 \mathrm{~Hz}$. Prior to each experiment, a chamber cleaning step $\left(\mathrm{O}_{2}\right.$ plasma $)$ and a seasoning process on a bare $\mathrm{SiO}_{2}$ wafer were performed to ensure process reproducibility. The etch process was performed at $200 \mathrm{mT}$ with $200 \mathrm{sccm} \mathrm{Ar}, 45 \mathrm{sccm} \mathrm{CF} 4,5 \mathrm{sccm} \mathrm{CH}_{2} \mathrm{~F}_{2}, 600 \mathrm{~W}$ of plasma power, and $20 \mathrm{G}$ of magnetic field for $20 \mathrm{~s}$. The oxygen based process is performed at $75 \mathrm{mT}$ with $250 \mathrm{sccm} \mathrm{\textrm {O } _ { 2 }}$ and $200 \mathrm{~W}$ of plasma power without magnetic field for $30 \mathrm{~s}$. Both plasma processes have already been investigated for porous low-k etching ${ }^{11,18,19}$ and for resist stripping, ${ }^{10,20}$ respectively.

It is worth mentioning that the optical emission spectra in the v-UV region in real plasma etching conditions are extremely complex to measure and thus hardly known. For these reasons, very little relevant data on this topic can be found. ${ }^{21,22}$ According to Woodworth et al., the dominant emission lines in the $\mathrm{v}$-UV region with our plasma etching process $\left(\mathrm{CF}_{4} / \mathrm{CH}_{2} \mathrm{~F}_{2} / \mathrm{Ar}\right)$ likely originate from argon emission at $105 \mathrm{~nm}$ and hydrogen emission at $103 \mathrm{~nm}$ and $122 \mathrm{~nm}$. In addition, fluorine emission lines at $79 \mathrm{~nm}$ and $98 \mathrm{~nm}$, fluorocarbon emission lines (above $190 \mathrm{~nm}$ ), and carbon emission lines spread throughout the whole spectrum are also expected to significantly contribute to the plasma emission in the $\mathrm{v}-\mathrm{UV}{ }^{22}$ With regards to $\mathrm{O}_{2}$ plasma, the major emission lines are expected from oxygen around $130 \mathrm{~nm}$. For both plasma processes, additional emission lines at lower wavelengths may be present but have not been observed experimentally during plasma etching. Photon absorption in the etched materials depends on the material extinction coefficient and on the photon wavelength. The reader is referred to Figure 9 from Ref. 22 for photons absorption in silicon dioxide.

To investigate the impact of v-UV photons only onto the material, we partially covered the wafer with five $2 \mathrm{~mm}$ thick $\mathrm{MgF}_{2}$ windows directly placed on the wafer surface to block ions and radicals from the plasma. As a consequence, the material under the $\mathrm{MgF}_{2}$ window is only exposed to photons from the plasma. It is worth noting that the $\mathrm{MgF}_{2}$ windows have a cut-off wavelength of $120 \mathrm{~nm}$, therefore all the emission lines below $120 \mathrm{~nm}$, mentioned in the previous paragraph, were blocked as well. In addition to the $\mathrm{MgF}_{2}$ windows, one area of the wafer was covered by a piece of silicon wafer to block all plasma species (ions, neutrals, and photons) to preserve the pristine material. The rest of the wafer was fully exposed to the plasma as illustrated by the wafer schematic shown in Fig. 1.

\section{Characterization}

Film thickness (t) and density $(\rho)$ were characterized by specular X-ray reflectivity (XRR) using a diffractometer (X'Pert Pro MRD, Panalytical, Westborough, MA) equipped with a ceramic X-ray tube (wavelength $=0.154 \mathrm{~nm}$ ) and highresolution horizontal goniometer (reproducibility $\pm 0.0001^{\circ}$ ). The XRR scans (x-ray counts versus incidence angle) were fitted using the X'Pert Reflectivity software. A single layer model was used whenever possible to fit all films, except in cases of significant plasma damage, where multilayer models were required to properly fit the data. The layers were modeled as organosilicate materials with the following average composition $\mathrm{CH}_{3} \mathrm{SiO}_{2}$.

Chemical plasma damage was investigated by infrared spectroscopy using a Thermo Nicolet Nexus 670 FTIR spectrometer operating in transmission mode. All spectra were collected in the range of $650-4000 \mathrm{~cm}^{-1}$ at a Brewster's angle in the range of $52^{\circ}-56^{\circ}$, using p-polarized light. The different absorption bands were then assigned according to literature values.

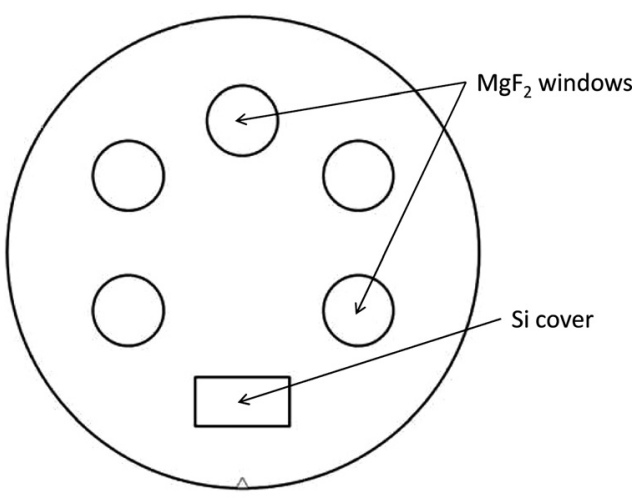

FIG. 1. Experimental wafer setup for plasma treatments. 
Film surface wettability was determined by contact angle measurement using a VCA $25000 \mathrm{XE}$ goniometer (AST products) and water as the probing liquid.

XPS analysis was done on a Physical Electronics Quantum 2000 ESCA Microprobe with a monochromatic Al Ka source, using charge neutralization. High resolution $(58.7 \mathrm{eV}$ pass energy, $0.5 \mathrm{eV} / \mathrm{step})$ scans were taken using a $200 \mu \mathrm{m}$ spot at $45^{\circ}$ angle between the sample and the analyzer axis.

\section{RESULTS AND DISCUSSION}

As illustrated in Fig. 1, for each plasma chemistry, samples with 3 different types of exposure were obtained after plasma treatment: no exposure (using the Si cover), v-UV radiation only $\left(\mathrm{MgF}_{2}\right.$ windows), or full exposure (uncovered). First, Si-covered pristine low-k coupons were characterized by XRR and the results are displayed in Table I. As expected, there is no difference between the two plasmas as the unfilled $\mathrm{k}=2.0$ material was not exposed to any ions, radicals, or v-UV photons from the plasmas. These results will be used as a reference for the pristine, unfilled $\mathrm{k}=2.0$ material.

\section{A. Impact of $v-U V$ photons on a unfilled $k=2.0$ low-k material}

Following pristine low-k characterization, the coupons that were exposed to $\mathrm{v}-\mathrm{UV}$ photons only $\left(\mathrm{MgF}_{2}\right.$ cover window) were also analyzed by XRR, which detects changes in density and thickness that are indicative of plasma damage. ${ }^{14}$ The results are summarized in Table II.

In the case of the fluorocarbon plasma, the sample does not display any significant difference in density, thickness, or scan shape compared to the equivalent pristine material, ${ }^{23}$ indicating that the porous dielectric material was not damaged by the fluorocarbon plasma v-UV photons. It is worth mentioning that the most intense $\mathrm{v}-\mathrm{UV}$ emission lines, which come from Ar (104-106 nm) and H (120 nm), were cut-off by the $\mathrm{MgF}_{2}$ window. Moreover, fluorine displays primarily low energy v-UV lines at $180-200 \mathrm{~nm}$. It is therefore not surprising that in the absence of strong v-UV emission, no damage to the dielectric material was detected. Conversely, the XRR scan of the unfilled, low-k material exposed to v-UV photons of the $\mathrm{O}_{2}$ plasma exhibits a different shape as compared to the pristine material. ${ }^{23}$ Data analysis of this scan requires a multi-layer fit, indicating that a denser layer has formed atop the pristine material. According to the fitting results, this layer is about $13 \mathrm{~nm}$ thick and $26 \%$ denser. Interestingly, the surface water contact angle only decreases from $83^{\circ}$ (pristine) to $74^{\circ}$ for the $\mathrm{v}$-UV exposed film,

TABLE I. Thickness and density of Si-covered (no exposure) unfilled $\mathrm{k}=2.0$ low-k materials.

\begin{tabular}{llllll}
\hline \hline \multirow{2}{*}{ Fitting model } & \multicolumn{2}{c}{$\mathrm{CF}_{4} / \mathrm{CH}_{2} \mathrm{~F}_{2} /$ Ar treatment } & & \multicolumn{2}{c}{$\mathrm{O}_{2}$ treatment } \\
\cline { 2 - 3 } \cline { 6 - 7 } & $\mathrm{t}(\mathrm{nm})$ & $\rho\left(\mathrm{g} / \mathrm{cm}^{3}\right)$ & & $\mathrm{t}(\mathrm{nm})$ & $\rho\left(\mathrm{g} / \mathrm{cm}^{3}\right)$ \\
\hline Layer 1 & 210.4 & 0.89 & & 209.3 & 0.89 \\
\hline \hline
\end{tabular}

TABLE II. Thickness and density data of the v-UV exposed, unfilled, $\mathrm{k}=2.0$ low-k material.

\begin{tabular}{lccccc}
\hline \hline & \multicolumn{2}{c}{$\mathrm{CF}_{4} / \mathrm{CH}_{2} \mathrm{~F}_{2} /$ Ar plasma } & & \multicolumn{2}{c}{$\mathrm{O}_{2}$ plasma } \\
\cline { 2 - 3 } \cline { 6 - 7 } Fitting model & $\mathrm{t}(\mathrm{nm})$ & $\rho\left(\mathrm{g} / \mathrm{cm}^{3}\right)$ & & $\mathrm{t}(\mathrm{nm})$ & $\rho\left(\mathrm{g} / \mathrm{cm}^{3}\right)$ \\
\hline Layer 2 & $\ldots$ & $\ldots$ & & 13.5 & 1.12 \\
Layer 1 & 209.3 & 0.91 & & 195.7 & 0.89 \\
\hline \hline
\end{tabular}

suggesting minimum bond cleavage and overall retention of the starting chemical composition. This was confirmed by the XPS surface analysis with similar C and O levels (29\% and $46 \%$, respectively) being measured for the pristine and the v-UV exposed samples. From the XRR data, 94\% of the film has kept the same density as the pristine material indicating that it was not damaged by the v-UV photons. While $\mathrm{v}-\mathrm{UV}$ damage from $\mathrm{O}_{2}$ plasma has been previously reported, ${ }^{24-26}$ it is difficult to quantitatively compare these literature results with ours since there are major differences in material composition, dielectric constant, and plasma conditions. In our case, only $6.5 \%$ of the total film thickness was damaged with a slight but significant increase in density. This suggests potential organosilicate backbone damage under v-UV exposure but retention of the porosity. This phenomenon has been previously described for broadband UV toughening of low-k materials. ${ }^{27-29}$ The change in organosilicate structure that occurs throughout the whole film thickness is typically followed by IR spectroscopy. The IR spectra of both the pristine and the $\mathrm{v}-\mathrm{UV}$ exposed $\mathrm{k}=2.0$ materials are presented in Fig. 2.

However, no apparent wavelength shift of the Si-O-Si bands $\left(1170-1030 \mathrm{~cm}^{-1}\right.$ region) or decrease in the peak intensity of the Si-C group at $1275 \mathrm{~cm}^{-1}$ is observed. We believe that FTIR is not sensitive enough to capture the impact of v-UV photons on the porous low-k material when the extent of reorganization is low (26\% density increase and slight contact angle decrease) and represents only $\sim 6 \%$ of the total film thickness.

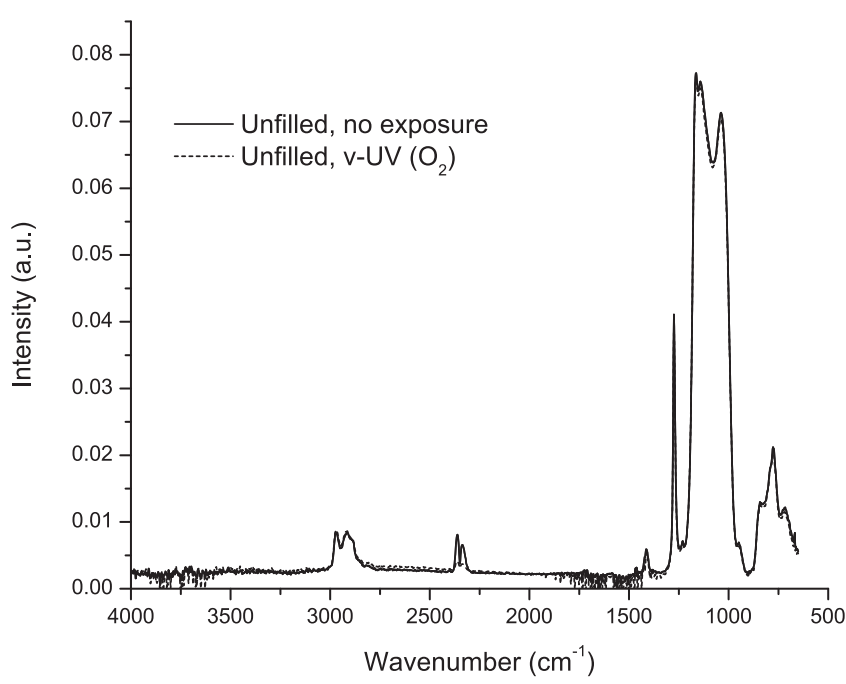

FIG. 2. Comparative FTIR spectra of the pristine and the v-UV exposed $\left(\mathrm{O}_{2}\right)$ porous dielectric material. 
In contrast, the complete effect of the $\mathrm{O}_{2}$ plasma (full exposure) to the low-k material chemistry can be directly observed by FTIR (Fig. 3). In that case, along with the appearance of hydrogen-bonded silanols at $3500 \mathrm{~cm}^{-1}$, the Si-O-Si peak shifts from $1036 \mathrm{~cm}^{-1}$ to $1066 \mathrm{~cm}^{-1}$ and a decrease of the $\mathrm{Si}-\mathrm{C}$ band is observed. These results support the loss of carbon covalently bonded to silicon. ${ }^{30}$ The surface becomes highly hydrophilic as evidenced by a change in water contact angle from $83^{\circ}$ (pristine) to less than $10^{\circ}$ for the fully exposed film. Corresponding XPS data measured on the same samples confirm the decrease in surface hydrophobicity: the carbon level drops from $29 \%$ to $2 \%$ and the $\mathrm{O}$ level increases from $46 \%$ to $70 \%$, suggesting that methyl groups and carbon bridges were cleaved and replaced by hydrophilic silanols.

The XRR data for the film fully exposed to an $\mathrm{O}_{2}$ plasma are reported in Table III. Similar to the effect of vUV only, a denser layer has formed atop the pristine material. According to the fitting results, this layer is about $10 \mathrm{~nm}$ thick but $136 \%$ denser and only $87 \%$ of the film has kept the same density as the pristine material. By calculation, $10 \mathrm{~nm}$ at a density of $2.1 \mathrm{~g} / \mathrm{cm}^{3}$ is equivalent to $24 \mathrm{~nm}$ at a density of $0.89 \mathrm{~g} / \mathrm{cm}^{3}$, which added to the undamaged film thickness of $181.7 \mathrm{~nm}$, is equal to $205.7 \mathrm{~nm}$. This value is relatively close to the initial pristine thickness of $209 \mathrm{~nm}$, indicating that little or no etching of the porous dielectric material occurred during $\mathrm{O}_{2}$ plasma exposure and that the difference in total thickness may be attributed to material densification.

The damage thickness has doubled from the v-UV treated sample $(\sim 13 \mathrm{~nm})$ to the fully exposed film $(\sim 24 \mathrm{~nm})$. Similarly, the density has changed from $1.12 \mathrm{~g} / \mathrm{cm}^{3}$ to $2.1 \mathrm{~g} / \mathrm{cm}^{3}$, indicating that the damage is a lot more severe for the fully exposed porous low-k material. This observation is in good agreement with previous studies showing a synergistic effect of the v-UV and ion bombardment. ${ }^{31,32}$ Thus, it is clear that v-UV only has an impact on the structure of the organosilicate. This effect is not easily detected with common characterization techniques but can be evidenced by

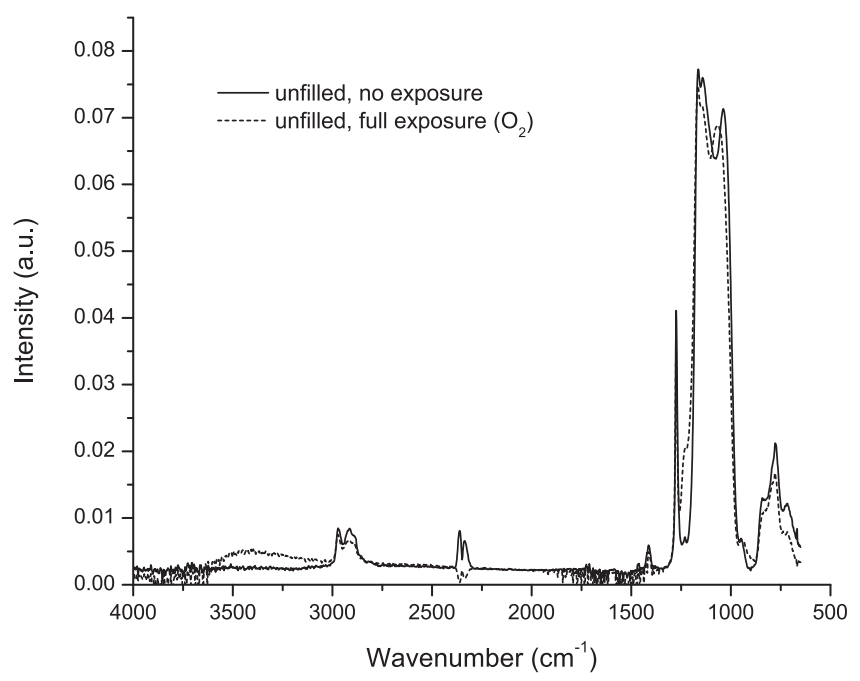

FIG. 3. Comparative FTIR spectra of the pristine and the fully exposed $\left(\mathrm{O}_{2}\right)$ porous dielectric material.
TABLE III. Thickness and density data of unfilled, $\mathrm{k}=2.0$ low-k material, fully exposed to the $\mathrm{O}_{2}$ plasma.

\begin{tabular}{lcc}
\hline \hline & \multicolumn{2}{c}{$\mathrm{O}_{2}$ plasma (full exposure) } \\
\cline { 2 - 3 } Fitting model & $\mathrm{t}(\mathrm{nm})$ & $\rho\left(\mathrm{g} / \mathrm{cm}^{3}\right)$ \\
\hline Layer 2 & 10.1 & 2.10 \\
Layer 1 & 181.7 & 0.92 \\
\hline \hline
\end{tabular}

$\mathrm{XRR}$, allowing us to investigate the $\mathrm{P} 4$ protective efficiency against v-UV damage.

\section{B. P4 efficacy against $v-U V$ damage}

In order to establish the P4 efficacy against v-UV damage, polymer filled low-k films were exposed to the more damaging $\mathrm{O}_{2}$ plasma based v-UV radiation. The filled porous low-k material was first characterized by XRR ( $\mathrm{Si}$ covered coupon) to get its reference thickness and density values. The XRR scan could be fitted using a single layer model, indicating that the pores were homogeneously filled. The film thickness and density were found to be $206 \mathrm{~nm}$ and $1.31 \mathrm{~g} / \mathrm{cm}^{3}$, respectively. The fill level $F$ was then calculated using

$$
\rho_{f-\text { diel }}=\rho_{\text {diel }}+(\nu \times F) \rho_{\text {filler }},
$$

where $v$ is the dielectric material porosity, $\rho_{\text {filler }}$ is the filler density, $\rho_{\text {diel }}$ is the pristine low-k density, and $\rho_{f \text {-diel }}$ the filled low-k density. For the present system, the calculation indicates a virtually complete pore filling of $93 \%$. The filled dielectric material was then exposed to $\mathrm{O}_{2}$ plasma v-UV photons only $\left(\mathrm{MgF}_{2}\right.$ window) and analyzed by XRR. Results for the filled and unfilled dielectric material after similar plasma exposure were then directly compared. The XRR data are shown in Table IV.

In contrast to the unfilled material, the XRR scan of the filled dielectric material after v-UV exposure could be fitted using one layer only, with similar thickness and density values as those of the reference filled coupon. This result alone already demonstrates that the $\mathrm{P} 4$ process provides ample protection of the dielectric material to this wavelength $\mathrm{v}-\mathrm{UV}$ radiation. Nevertheless, v-UV damage to the polymer filler could not be ruled out. Indeed, previous studies point to the v-UV sensitivity of PMMA, leading to bond scissions and/or cross-linking. ${ }^{33,34}$ In order to assess if the filler was in fact damaged during v-UV exposure, two additional experiments were conducted. First, a dynamic rinse of the filled sample surface using propylene glycol n-propyl ether (a very good solvent of the PMMA-like filler) was performed. If

TABLE IV. Thickness and density results of filled and unfilled $\mathrm{k}=2.0$ low-k material after exposure to v-UV from the $\mathrm{O}_{2}$ based plasma.

\begin{tabular}{lccccc}
\hline & \multicolumn{2}{c}{ Without P4 protection (unfilled) } & & \multicolumn{2}{l}{ With P4 protection (filled) } \\
\cline { 2 - 3 } \cline { 5 - 6 } Fitting model & $\mathrm{t}(\mathrm{nm})$ & $\rho\left(\mathrm{g} / \mathrm{cm}^{3}\right)$ & & $\mathrm{t}(\mathrm{nm})$ & $\rho\left(\mathrm{g} / \mathrm{cm}^{3}\right)$ \\
\hline Layer 2 & 13.5 & 1.12 & & $\ldots$ & $\ldots$ \\
Layer 1 & 195.7 & 0.89 & & 204.8 & 1.31 \\
\hline \hline
\end{tabular}


significant filler bond scission occurred, the filler molecular weight should be reduced, making the filler inside the pores prone to solvent rinse out. ${ }^{14}$ However, no change in density was observed by XRR after the solvent rinse, indicating that filler wash out was negligible. Second, a thermal treatment at $400{ }^{\circ} \mathrm{C}$ under $\mathrm{N}_{2}$ (referred to as "burn-out") was performed on the filled, v-UV exposed sample to determine if complete filler decomposition and removal had occurred. While complete removal would indicate only linear or partially cleaved chains were present, cross-linked materials tend to leave char residue, and correspondingly higher density values. From the XRR data, the bulk density after burn-out was found to be $0.903 \mathrm{~g} / \mathrm{cm}^{3}$, a value very close to that of the pristine porous low-k material which indicates that the filler was fully eliminated and that it efficiently protected the porous low-k film. Based on these observations, it is unlikely that major changes were affected by the v-UV radiation of a real integration $\mathrm{O}_{2}$ plasma. In the least, minor changes do not appear to negatively impact either overburden removal or thermal decomposition efficacy.

\section{CONCLUSION}

v-UV damage of highly porous dielectric materials strongly depends upon the plasma chemistry, and more specifically on the energy and intensity of the different plasma emission lines. In the case of etching plasmas such as $\mathrm{CF}_{4} / \mathrm{CH}_{2} \mathrm{~F}_{2} /$ Ar, only low energy v-UV emission lines were able to pass through the $\mathrm{MgF}_{2}$ window. Consequently, no porous dielectric material damage was evidenced. On the other hand, more energetic v-UV radiation derived from the $\mathrm{O}_{2}$ plasma treatment resulted in dielectric material damage in the form of a thin denser layer, which could only be detected by XRR. The P4 efficacy against $\mathrm{v}$-UV damage from an $\mathrm{O}_{2}$ integration plasma was clearly demonstrated by lack of this denser top layer. In addition, no significant filler damage, which would negatively impact the overall $\mathrm{P} 4$ process flow (such as overburden removal and filler thermal decomposition) was observed.

\section{ACKNOWLEDGMENTS}

The authors wish to thank Leslie E. Thompson for technical assistance and Marc Fouchier for useful discussions about plasma and v-UV emission.

${ }^{1}$ W. Volksen, R. D. Miller, and G. Dubois, Chem. Rev. 110(1), 56 (2010).

${ }^{2}$ G. Dubois, W. Volksen, T. Magbitang, R. D. Miller, D. M. Gage, and R. H. Dauskardt, Adv. Mater. 19(22), 3989 (2007).

${ }^{3}$ G. Dubois, W. Volksen, T. Magbitang, M. H. Sherwood, R. D. Miller, D. M. Gage, and R. H. Dauskardt, J. Sol-Gel Sci. Technol. 48(1-2), 187 (2008).

${ }^{4}$ W. Volksen, T. P. Magbitang, R. D. Miller, S. Purushothaman, S. A. Cohen, H. Nakagawa, Y. Nobe, T. Kokubo, and G. J. M. Dubois, J. Electrochem. Soc. 158(7), G155 (2011).
${ }^{5}$ W. Volksen, S. Purushothaman, M. Darnon, M. F. Lofaro, S. A. Cohen, J. P. Doyle, N. Fuller, T. P. Magbitang, P. M. Rice, L. E. Krupp, H. Nakagawa, Y. Nobe, T. Kokubo, and G. J. M. Dubois, ECS J. Solid State Sci. Technol. 1(5), N85 (2012).

${ }^{6}$ S. M. Gates, G. Dubois, E. T. Ryan, A. Grill, M. Liu, and D. Gidley, J. Electrochem. Soc. 156(10), G156 (2009).

${ }^{7}$ Y. Matsuda, J. S. Rathore, L. V. Interrante, R. H. Dauskardt, and G. Dubois, ACS Appl. Mater. Interfaces 4(5), 2659 (2012).

${ }^{8}$ M. S. Oliver, G. Dubois, M. Sherwood, D. M. Gage, and R. H. Dauskardt, Adv. Funct. Mater. 20(17), 2884 (2010).

${ }^{9}$ J. S. Rathore, L. V. Interrante, and G. Dubois, Adv. Funct. Mater. 18(24), 4022 (2008).

${ }^{10}$ N. Posseme, T. Chevolleau, T. David, M. Darnon, O. Louveau, and O. Joubert, J. Vac. Sci. Technol., B 25(6), 1928 (2007).

${ }^{11}$ M. Darnon, N. Casiez, T. Chevolleau, G. Dubois, W. Volksen, T. J. Frot, R. Hurand, T. L. David, N. Posseme, N. Rochat, and C. Licitra, J. Vac. Sci. Technol., B 31(1), 011207 (2013).

${ }^{12}$ R. L. Bruce, S. Engelmann, S. Purushothaman, W. Volksen, T. J. Frot, T. Magbitang, G. Dubois, and M. Darnon, J. Phys. D: Appl. Phys. 46(26), 265303 (2013).

${ }^{13}$ W. Volksen, K. Lionti, T. Magbitang, and G. Dubois, Scr. Mater. 74, 19 (2014).

${ }^{14}$ K. Lionti, W. Volksen, T. Magbitang, M. Darnon, and G. Dubois, ECS J. Solid State Sci. Technol. 4(1), N3071 (2015).

${ }^{15}$ T. Frot, W. Volksen, S. Purushothaman, R. Bruce, and G. Dubois, Adv. Mater. 23(25), 2828 (2011).

${ }^{16}$ T. Frot, W. Volksen, T. Magbitang, S. Purushothaman, R. L. Bruce, S. Cohen, M. Lofaro, and G. Dubois, Future Fab Intl. 39, 67 (2011).

${ }^{17}$ T. Frot, W. Volksen, S. Purushothaman, R. L. Bruce, T. Magbitang, D. C. Miller, V. R. Deline, and G. Dubois, Adv. Funct. Mater. 22(14), 3043 (2012).

${ }^{18}$ N. Posseme, T. Chevolleau, O. Joubert, L. Vallier, and N. Rochat, J. Vac. Sci. Technol., B 22(6), 2772 (2004).

${ }^{19}$ D. Eon, M. Darnon, T. Chevolleaua, T. David, L. Vallier, and O. Joubert, J. Vac. Sci. Technol., B 25(3), 715 (2007).

${ }^{20}$ M. Darnon, T. Chevolleau, T. David, N. Posseme, J. Ducote, C. Licitra, L. Vallier, O. Joubert, and J. Torres, J. Vac. Sci. Technol., B 26(6), 1964 (2008).

${ }^{21}$ J. R. Woodworth, M. G. Blain, R. L. Jarecki, T. W. Hamilton, and B. P. Aragon, J. Vac. Sci. Technol., A 17(6), 3209 (1999).

${ }^{22}$ J. R. Woodworth, M. E. Riley, V. A. Arnatucci, T. W. Hamilton, and B. P. Aragon, J. Vac. Sci. Technol., A 19(1), 45 (2001).

${ }^{23}$ See supplementary material at http://dx.doi.org/10.1063/1.4915508 for XRR scans.

${ }^{24}$ J. Lee and D. B. Graves, J. Vac. Sci. Technol., A 31(4), 041302 (2013).

${ }^{25}$ J. Lee and D. B. Graves, J. Phys. D: Appl. Phys. 44(32), 325203 (2011).

${ }^{26}$ H. Kazi and J. A. Kelber, J. Vac. Sci. Technol., A 32(2), 021302 (2014).

${ }^{27}$ D. M. Gage, J. F. Stebbins, L. Peng, Z. Cui, A. Al-Bayati, K. P. MacWilliams, H. M'Saad, and R. H. Dauskardt, J. Appl. Phys. 104(4), 043513-1 (2008).

${ }^{28}$ Y. Lin, Y. Xiang, T. Y. Tsui, and J. J. Vlassak, Acta Mater. 56(17), 4932 (2008).

${ }^{29}$ A. Zenasni, B. Remiat, C. Waldfiied, C. Le Cornec, V. Jousseaume, and G. Passemard, Thin Solid Films 516(6), 1097 (2008).

${ }^{30}$ P. H. T. Ngamou, J. P. Overbeek, R. Kreiter, H. M. van Veen, J. F. Vente, I. M. Wienk, P. F. Cuperus, and M. Creatore, J. Mater. Chem. A 1(18), 5567 (2013).

${ }^{31}$ J. Shoeb, M. M. Wang, and M. J. Kushner, J. Vac. Sci. Technol., A 30(4), 041303 (2012).

${ }^{32}$ J. Lee and D. B. Graves, J. Phys. D: Appl. Phys. 43(42), 425201 (2010).

${ }^{33}$ F. E. Truica-Marasescu and M. R. Wertheimer, Macromol. Chem. Phys. 206(7), 744 (2005).

${ }^{34}$ M. R. Wertheimer, A. C. Fozza, and A. Hollander, Nucl. Instrum. Methods Phys. Res., Sect. B 151(1-4), 65 (1999). 